\title{
Interorganizational Relationship among Government, Industry and Academia in the Japanese Public Water Services: Compatibility and Motivation in Interorganizational Settings
}

\section{Kazunori Kamitani*}

Graduate School of Technology Management Ritsumeikan University

1-1-1 Nojihigashi, Kusatsu-city, Shiga, Japan

E-mail gr040050@ed.ritsumei.ac.jp

* Corresponding author

\section{Shuichi Ishida}

Graduate School of Technology Management Ritsumeikan University

1-1-1 Nojihigashi, Kusatsu-city, Shiga, Japan

E-mail syuich@ca2.so-net.ne.jp

\section{Takashi Natori}

Graduate School of Technology Management Ritsumeikan University

1-1-1 Nojihigashi, Kusatsu-city, Shiga, Japan E-mail natori@fc.ritsumei.ac.jp

\section{Tomoyuki Nishimura}

Kushiro Public University of Economics 4-1-1 Ashino, Kushiro-city, Hokkaido, Japan E-mail nisimura@kushiro-pu.ac.jp

\begin{abstract}
This study analyses government-industry-academia collaboration in Japan from the view point of compatibility and motivating factors to collaborate among partners. The primary purpose of this study is to find out the strategic motivating factors of government in the government-industryacademia collaboration. This study investigates the strategic motivation by assessing the factors of takeout incentives, in-house incentives, exploration and exploitation. A theoretical model that includes these factors is tested using 2009 data collected from public water supply services in Japan $(n=685)$. As a result, it is made clear that the in-house incentives represented by the "advantages for the growth of the waterworks industry" and the "advantages for future vater supply" are linked to the outcome represented by "water supply revenue trends" through the mediation of government leadership. Considering the results of this study, it is understood that the strategic motivation are not directly related to government-industry-academia collaboration outcomes, but rather it is the leadership of government leadership that is important for the outcomes.
\end{abstract}


Keywords: collaboration Government, Industry and Academia; strategic motivation; incentives; takeout incentives; in-house incentives; learning motivation; exploration; exploitation; autonomous collaborative system; organizational characteristics; complementarity in resources;

Biographical notes: Kazunori Kamitani received the B.Sc. degree in economics from Ritsumeikan University, Shiga, Japan, in 1984, and the M. Sc. degree in technology management from Ritsumeikan University, Shiga, Japan, in 2007. $\mathrm{He}$ is currently working toward the Ph.D. degree in technology management from Ritsumeikan University, Shiga, Japan. From 1984 to 1994, His current research interests include inter-organizational relationship and the government-industry-academia collaboration.

Shuichi Ishida received his $\mathrm{PhD}$ in Business Administration from Hokkido University and in Engineering from Kyoto University. He is currently a Professor at the Graduate School of Technology Management, Ritsumeikan University. His teaching courses are in technology management and social systems research. His current research interests include organizations and strategies on MOT.

Takashi Natori received his $\mathrm{PhD}$ in Engineering from Tohoku University. He is currently a Professor at the Graduate School of Technology Management, Ritsumeikan University. His fields of specialization are in applied economics, fiscal studies/finance theory and business administration. His current research interests include technology management, small-and medium-sized enterprises, venture business and innovations in local areas.

Tomoyuki Nishmura received his $\mathrm{PhD}$ in Business Administration from Hokkido University. He is currently an Associate Professor at the Kushiro Public University of Economics. His teaching courses are in business management theory and management strategic theory. His current research interests include organization and environment, inter-organizational development.

\section{Introduction}

This study analyzes government-industry-academia collaboration in Japan from the view point of compatibility and motivating factors to collaborate among partners. It is a daunting task to analyze the primary factors that contribute to a successful governmentindustry-academia collaboration using the two-dimensional-framework of resource based and organizational structure proposed by Parkhe (1991). The obvious differences in their organizational composition make it difficult to assess the possibility of success when government-industry-academia collaboration is analyzed using the two-dimensionalframework. In short, the constituting elements of each independent organization, whose members have their own sense of purpose and essence of existence, will naturally differ in some aspects Kanai (2004). Institutional culture and working style differences among collaborators could prevent the necessary development of social harmony and invite huge costs that would be needed to create synergy..

Based on this observation, the question begs whether there is any policy which can lead to a successful government-industry-academia collaboration in spite of the inter- 
organizational differences. Thus, this study analyzes the partnership compatibility based on three-dimensional-framework that includes strategic motivation dimension.

Nishimura(2010) infers that the ideal situation for a smooth relationship among the collaborating partners is characterized by "similarity in strategic motivation, complementarity in resources, and also similarity in organizational characteristics." Further more Teramoto (1987) pointed out that a long term collaboration becomes difficult and that the probability of success decreases in case where there are conceptual differences in the strategic positioning of the collaborating partners even though the collaborating partners have similar resources and exhibit similar organizational characteristics.

Drawing from the above statements, we analyze the partnership of governmentindustry-academia collaboration. First of all, Terada and Kanda(1991) indicated that there are two kinds of complementarity in resources: (1) heterogeneous collaboration such as the co-development based on different technical resources or derived from different functions that include manufacturing and sales, (2) homogeneous complementarity which is made by the integration of homogeneous resources such as sharing developing funds and the joint use of production facilities.

Further more, in government-industry-academia collaboration, the difference in organizational characteristics can be clearly seen depending on the differences in the institution's perception of its objectives, and on the institution's reason for existence of each organization. After gaining an understanding of the differences on organizational characteristics, it is then necessary to focus on strategic motivation that can lead to the establishment of a successful government-industry-academia collaboration. Thus the primary purpose of this study is to find out the strategic motivating factors for collaboration of the government in the government-industry-academia collaboration.

\section{Previous Research}

\subsection{Current conditions and issues facing public water supply services in Japan}

Over 120 years have passed since Japan established its modern domestic water supply services, and today almost everyone in Japan can safely drink tap water. However, due to various issues currently facing Japan including low birth rates, an aging population, measures needed to address environmental issues and weather changes, resource and energy pressures, and a stagnant market economy, it is becoming difficult for water supply services to address pressing matters in the regard to securing human resources for management, technological inheritance, and the renovation of aging equipment. There is also an increasing recognition of the positions of water as a strategic material that is important for national security, alongside food and energy. Both the public and the private sectors alike demand swift action in the areas to overseas development of water supply services and sustainable water services that can be carried to the next generation. Therefore, the ways in which public and private collaborative partnerships are formed are an important key in addressing the issues faced by the water services industry. (Japan Water Research Center, 2011)

The Japanese water service industry has for many years upheld the safety and security of Japan's water services, and possesses world-class technologies and know-how. Even in the present difficult business environment they must continuously grow and develop, 
uphold the trustworthiness of the water supply services, and make broad contributions to society. Additionally, they must be flexible to the demands of the times and take necessary reforms. The foundation of water service in Japan is based on the ideal of cleaning and supplying abundant and inexpensive water to all of the people in the country. Even in adhering to this ideal there is a demand for a positioning by which not only domestic but also global contributions are made through the proactive development and supply of advanced technologies, products and know-how. (Water Industry Strategic Conference, 2008)

Generally water supply services in Japan are run by public entities. They were set up through local government administration using the technology and facilities of domestic water supply companies. In the future, there is a possibility that government-industryacademia collaboration, where local government plays an important role, will become a new model of local government leadership involvement when more similar collaboration take place including privatization efforts. Thus it will be necessary to reinforce management practices coupled with the promotion of public-private collaboration in order to fill up the accelerated hollowing-out of technology and to also streamline management.

Considering the above, it is our wish to provide new insight by investigating the possibilities of new government-industry-academia collaborations by conducting a research of Japanese water project collaborations, including government-private sector and industry-academia collaborations, as these water projects possess both urgent and important issues.

\subsection{Government-Industry-Academia Collaboration}

According to Henry Etzkowitz (2008), the triple helix' approach is a social framework of the integrated composition of each constituting element; in other words, it is a platform to create a new organization (institution) that promotes innovation.

Under the centralized government system model, government usually plays the role of a leader. In this model, government is expected to play the role as a leader when initiating a project or providing resources for carrying out new services. In the laissez-faire model, the expected government role limited to roles such as imposing legal restrictions and purchasing products. Government is expected to engage as a private entity only in situations where the market is not able to make all necessary provisions.

As mentioned above, government has a significant role to play in the collaboration efforts, the water supply services in Japan analyzed in this study are public services entities which are run by local governments. Therefore within the collaboration the role of government is quite prominent in the running of the services.

Industry-academia collaboration is the interaction between an enterprise and a university, two institutions that have differing mandates and objectives. Through their interactions, these institutions make adjustments to fill in the gaps that exist between their organizational structures that result in enterprises, markets and industries being formed based on the collaborative relationship between the institutions (Watanabe et al., 2008). In this regard it is imperative to appreciate the areas of differences, and based on that understanding, craft a management process that can be used to fill in the structural and institutional gaps.

Furthermore, it can be said that government-industry-academia collaboration is loosely bound organizational network collaboration (Weick 1976). Otaki et al. (1997) 
defines this from the standpoint of strategic theory as a multiple independent aggregate organization working in close cooperation for the purposes of assisting and complementing each other's network organization. In this kind of organization each constituent member taking part in the collaboration has a main profession, and therefore even for some reason the collaboration becomes redundant, the members are in no threat of losing their main profession. This suggests that within the network organization the constituent members are first committed to their main occupations and thus it becomes difficult to ensure collaborative willingness among constituent members.

The next, look at the motivational factors that enhance cooperation and which leads to an impetus to collaborate.

\subsection{Classification of Strategic motivation}

There also exists the issue in the motivation of the enterprise in entering a strategic collaboration and the compatibility of the enterprise members as collaboration partners.

According to Teramoto (1987), the issue revolving around the compatibility of the collaborating partners should be analysed within the three dimensions of strategies, resources, and organizational characteristics. On the other hand, a majority of the previous related studies emphasized the selection of partners by focusing mainly on the latter two dimensions, namely resources and organizational characteristics. However, strategic collaboration is important because without strategy, the collaboration might not be able to establish a competitive advantage. (Nonaka, 1991). In this respect this study will not employ the dominant two-dimensional-framework that is composed of resources and organizational characteristics but rather utilize Teramoto's (1987) three-dimensionalframework which incorporates strategy as an analytical dimension.

Nishimura (2010) investigated the differences in motivation between collaboration partners and its relationship to insecurity within the collaboration. Here three conceptual groups were utilized: (a) the learning classification of exploration vs. exploitation as the motivation of the collaboration (March, 1991); (b) the collaborative classification of scale vs. link (Hennart, 1988); and (c) the benefit classification of private benefit vs. common benefit (Khanna, Gulati, and Nohria, 1998).

(a)The learning classification. First, March (1991) applies the learning classification of exploration vs. exploitation. Exploration is the search for new knowledge, and exploitation is the usage and development of previous knowledge.

(b)The collaborative classification. Due to the differences in the collaboration between the partners, two broad classifications can be made. The best known of these is the link versus scale dichotomy put forward by Hennart (1988). In a link-based collaboration, the first enterprise provides the technical skills and the second enterprise provides the sales skills. In this collaboration type, a linkage of differing resources and skills are sought. In a scale-based collaboration, partners contribute resources for the same stage in the value chain in order to achieve economies of scale or surplus manufacturing capabilities (Dussauge, Garrette, and Mitchell, 2000).

(c)The benefit classification. There is a diverse array of benefits associated with collaboration, and two broad and qualitatively differing classifications can be made (Khanna, 1998). The two types of benefits are called private benefits and common benefits. Private benefits are unilateral benefits gained when the enterprise acquires skills from the partner which are then applied in a work area of the enterprise unrelated to the 
activities of the collaboration. Common benefits are collaboratively created benefits in an area related to the activities of the collaboration (Sarker et al., 2001).

Through the application of the Theory of Organizational Equilibrium created by Barnard (1938), Nishimura (2005) conceptualizes network organization not as the collaborative system of the hierarchy organization, but rather as the autonomous collaborative system. The autonomous collaborative system is formed from two domains: (1) the autonomous domain that defines the main profession (2) the collaborative domain in which collaborative work takes place.

The incentive gained by participating in the collaborative domain is classified into "in-house incentive" and "takeout incentive." This study will briefly mention "in-house incentive" and "takeout incentive" as a measure of common-benefit and private -benefit.

Dussauge, Garrette, and Mitchell (2000) extracted an implication of the research performed by Koza and Lewin (1998), stating that differing collaboration types provide opportunities primarily in either explorative learning or in exploitative learning. The collaboration type and the leaming (motivation) type were stated to correspond in that enterprises primarily acquire exploration opportunities in link-based collaborations, and exploitation opportunities in scale-based collaborations. Additionally, partner enterprises have a significantly higher probability of acquiring private benefits with link-based collaborations than they do with scale-based collaborations (Dussauge, Garrette, and Mitchell, 2000). As a result, link-based collaborations can be characterized as having high private- to common-benefit ratios, and scale-based collaborations can be characterized as having low private- to common-benefit ratios.

Table 1 Comparison between link-based collaboration and scale-based collaboration

\begin{tabular}{|c|c|c|}
\hline & \multicolumn{2}{|c|}{ Nishimura (2010) } \\
\hline Learning motivation & Exploration & Exploitation \\
\hline Private- to Common-Benefit Ratios & High & Low \\
\hline $\begin{array}{c}\text { Characteristics of Resource } \\
\text { Complementarity }\end{array}$ & $\begin{array}{c}\text { Heterogeneous } \\
\text { Collaboration }\end{array}$ & $\begin{array}{c}\text { Homogeneous } \\
\text { Complementarity }\end{array}$ \\
\hline
\end{tabular}

According to the previous studies, do the partners in the government-industry-academia collaboration demonstrate the types of motivation mentioned on link-based collaboration (Table 1)? In particular, government's motivation to participate in the governmentindustry-academia collaboration has to be examined.

\section{Hypotheses}

According to the classification found in Table 1 by Nishimura (2010), Governmentindustry-academia collaboration falls under the link-based collaboration where resource characteristics lead to heterogeneous complementarity. Managing the link-based collaboration that is capable of handling various forms of and the fast changing business environment is difficult when compared to the existing scale-based collaboration that pursues scale economy such as expanding market share, since in the link based collaboration, the limits and boundaries of each enterprise's involvement are ambiguous, 
and accordingly the strategic motivation differs from the partners. In other words, under this kind of unsymmetrical setting where one aims at exploration and the other aims at exploitation, we need to pay attention to the kind of dynamics that can work within the collaboration.

Further more we analyze both the takeout and in-house incentives. The advantage of applying takeout and in-house incentives to organizational analysis is stated by Nishimura(2008) as follows: two kinds of incentives can be classified conceptually, but it is not certain whether people can actually perceive the difference between them. One of the reasons is that an in-house incentive can also be a takeout incentive at the same time, and people might not be able to differentiate one from the other. As it is generally believed that the classification of incentives is based on analytical approach and that the same issues can be explained differently depending on the dimension (Nishimura, 2006b; Poole and Ven 1989), the classification of in-house and takeout incentives might be useful to describe the phenomena among organization by using it as two independent ways of analysis. Never the less it is necessary for us to pay attention to not only to the importance placed between the two incentives mentioned above but also to the complementing factors that exist among them. In reality these two kinds of incentives are closely linked and are usually presented together. Nishimura(2004a) argued that motivation for collaboration should increase by adding in-house incentive to takeout incentive. By integrating them after separating the targets for observation, it becomes possible for us to have a clearer understanding, which would otherwise have gone unnoticed if the processes were not followed. Therefore the approach of dividingintegration shouldn't be underestimated.

The relation between the motivation to learn, and the incentive of the partners participating in the government-industry-academia collaboration is compiled in Figure 1.

Figure 1 A conceptual model of principal domain collaborating members

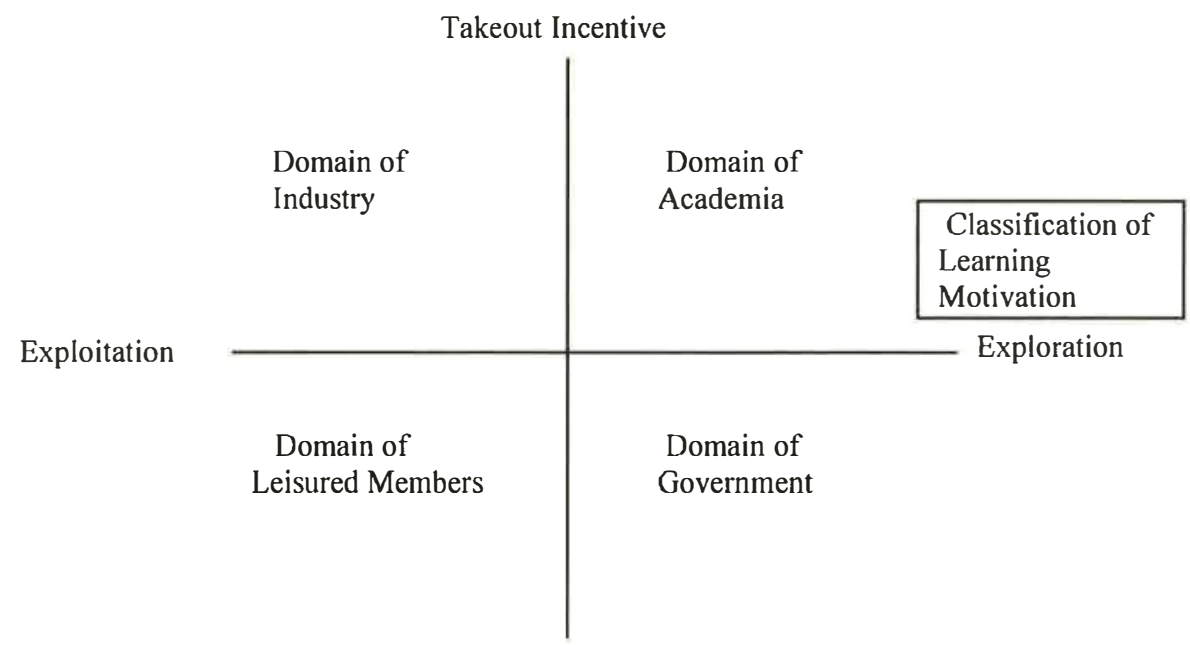

In-house Incentive

Classification of Incentive 
The framework of this concept is to describe the domain in which the incentives given to the partners of government-industry-academia are placed on the matrix that is composed of both takeout/in-house incentives in one plane and exploration/exploitation placed on the other plane.

Takeout incentives are emphasized for Industry, while academia is also paying more attention to takeout incentives with the ongoing incorporation of national universities.

There is a study regarding the differences felt by industry and academia regarding whether "research aspect industry-academia collaborations" or "commercialization aspect industry-academia collaborations" are the most meritorious. Lee (2000) states that American universities place importance on the research aspect of industry-academia collaborations, and focus on "research funds," including pay for assistants, funds for research equipment, and supplementary research capital, as well as "research know-how," including research suggestions and theoretical on-site investigations. In Japan as well, the acquisition of research funds and know-how are given as merits for the university in industry-academia collaborations (Harayama et al., 2003; Baba et al., 2007). However, American enterprises do not place importance only on accessing new research, maintaining relationships with the academic world, and other research aspects of industry-academia collaborations. They also place importance on the commercialization aspect of industry-academia collaborations, including the development of new products and methods, the acquisition of new patents, the resolution of technical issues, and quality improvement. The expectations of Japanese companies almost mirror those of their American counterparts, and list as merits of industry-academia collaboration the ability to carry out high-risk and advanced technical research, technical guidance, the provision of the latest information, enterprise researcher training, and maintenance of relationships with the academic world, and the hiring of students (Harayama et al., 2003). It is recognized that there is a gap in the merits sought by the university and those sought by the enterprise. In this regard when it comes to which is government given more incentive, exploration or exploitation?

Kamitani and Ishida (2008) carried out a study on orientations of collaborative willingness in government-industry-academia collaboration within strategic motivation. In that study a difference in exploration or exploitation as the strategic motivation was seen between the constituent members, stemming from differences in goal awareness and expected outcomes. Furthermore in the area of benefits, a takeout incentive conflict arose which became a contributing factor in lowering willingness to collaboration. For these reasons we think that management is important for issues such as strategic motivational changes that occur over time, and the differing orientation of benefits perceived in the inhouse and takeout incentive.

Many studies on industry-academia collaboration have been undertaken, but only a few studies touch on government involvement. Henry Etzkowitz (2008) concurred by stating that "we face limitations in developing the relationship between academia and industry without considering the role of government," it is essential to analyse the motivating factors that influence government to participate in government-industryacademia collaboration.

Basing on the classifications presented in Table 1, we set up a survey to try and find out the motivating factors that lead govemment to collaborate with industry and academia. The survey is based on the following hypotheses 
Hypothesis 1 Takeout incentives will be positively associated with the outcomes.

Hypothesis 2 In-house incentives will be positively associated with the outcomes.

Hypothesis 3 Strategic motivations will be positively associated with the outcomes.

Hypothesis 4 Leadership will strengthen the positive relationship between takeout incentives and the outcomes.

Hypothesis 5 Leadership will strengthen the positive relationship between in-house incentives and the outcomes.

Hypothesis 6 Leadership will strengthen the positive relationship between strategic motivations and the outcomes.

As stated above, Figure 2 presents the framework, used to analyze the strategic motivation in industry-academia-government collaboration, it shows the dichotomy division of learning motivation and incentives, and also the effectiveness of collaboration.

Figure 2 A conceptual model of the role of incentives/motivation and leadership in collaboration

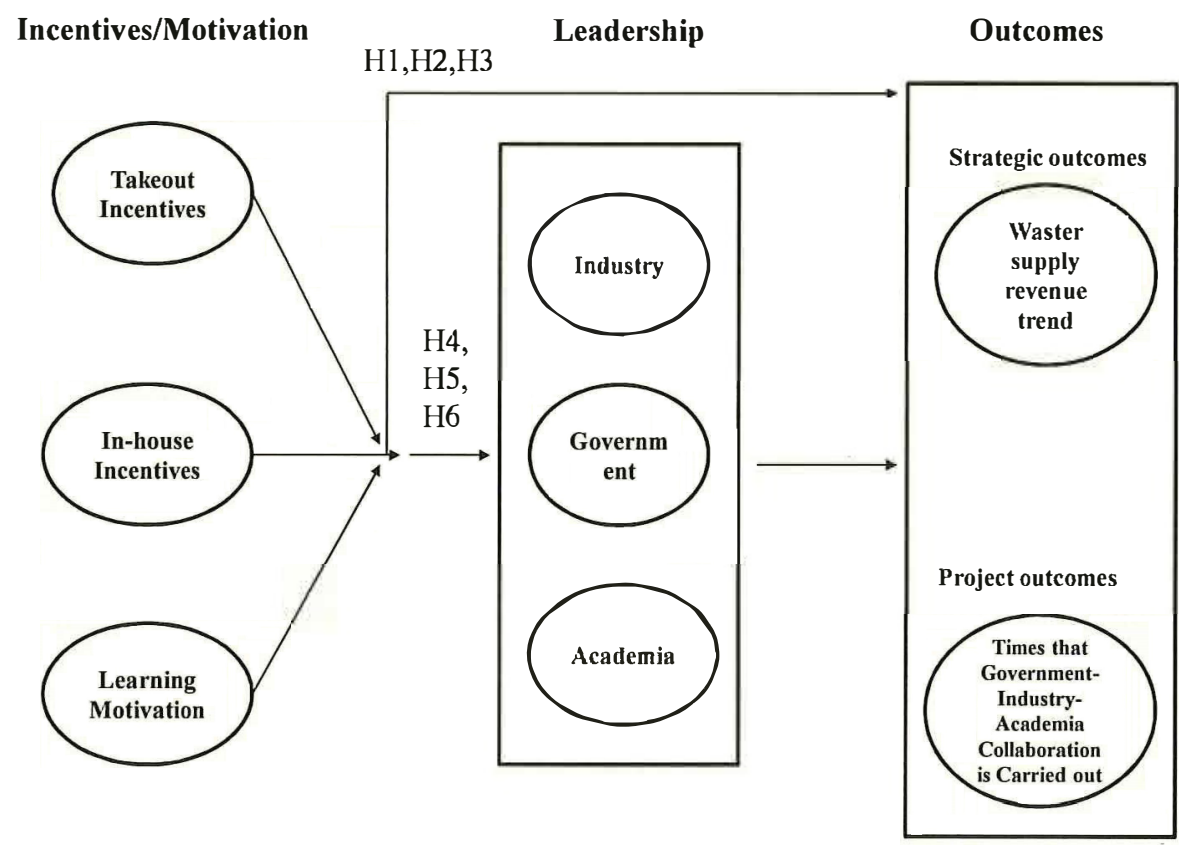




\section{Research Method}

Subjects of the investigation included 1,473 water-supply corporations throughout Japan. A questionnaire investigation was conducted targeting these subjects, and the results of the investigation were then statistically analyzed. The investigation was conducted over a one month period from November 2009 to December 2009. 740 responses were collected, 685 of which were valid responses (a valid response collection rate of $46.5 \%$ ).

We used Partial Least Squares (PLS). PLS, also called "soft modelling" (Lohmoller 1989), estimates latent variables as exact linear combinations of observed measures and therefore assumes that all measured variance is useful variance to be explained. PLS makes minimal demands on sample size (Barclay and Smith 1977), thus make it especially appropriate for testing structural models with relatively smaller sample sizes.

Although PLS estimates both factor loading and structural paths simultaneously, we followed the procedure advocated by Hulland (1999) in evaluating PLS models. The estimated model was analyzed and interpreted in two stages: (a) the assessment and reliability of the measurement model and (b) the testing of the structural model. We assessed the adequacy of the measurement model through examining individual-item reliabilities, the convergent validity of the measures associated with each construct, and assessing their discriminant validity.

Since PLS does not attempt to minimize residual item covariance, there is no summary statistic to measure the overall fit of models as in the case of SEM techniques. Variance explained $\left(\mathrm{R}^{2}\right)$ and the sign and significance of path coefficients are used to assess nomological validity. A bootstrapping method of "sampling with replacement" was used to assess the statistical significance of the parameter estimates. Standard errors were computed on the basis on 500 bootstrapping runs.

Question items included four questions regarding takeout incentives, three questions regarding in-house incentives, one question regarding explorative strategy, one question regarding exploitative strategy, and three questions regarding leadership. All the items used to measure the constructs were closed-ended with 7-point Likert-type scales of strongly agree to strongly disagree.

On the questionnaire sheet, the number of times that government-industry-academia collaboration is carried out and revenue trends within water supply corporations were used as the index of government-industry-academia collaboration outcomes.

Explanatory variables for strategic motivation factors within government-industryacademia collaborations were given as the following takeout incentives for the autonomous domain: "fund-related advantages," "knowledge acquisition-related advantages," "human resources development-related advantages," and "network development-related advantages." Furthermore, as personal satisfaction factors gained by the constituent members in the collaborative domain, the in-house incentives of "advantages for the growth of the waterworks industry," "advantages for future water supply," and "value of participation in itself" were given.

The primary factors that constitute takeout incentives and in-house incentives deduced from the concept of autonomous collaboration system that was mentioned before by Nishimura (2005) are cited. Takeout incentives are what are fed back from the collaboration domain to the autonomous domain, where tangible/ intangible inputs that include knowledge, validity, mediation and introduction, right, financial resources are shown. In-house incentive found in the collaborative domain express the member's 
individual satisfaction in regard to ideal benefits, feelings towards colleagues, prestige and honour and the feeling of participation in what is going on.(Barnard. 1938)

In addition to these the "research-related advantages" of exploration and the "commercialization-related advantages" of exploitation were presented as items.

Additionally an item was included that asked the respondent to give their opinion as to whether "industry," "academia," or "government" had the greatest influence on strategic motivation. (Table 2)

For the results of each factor in the questionnaire investigation an analysis was conducted to determine the influence of that factor on the number of times that government-industry-academia collaboration is carried out and water supply revenue trends.

Table 2 Measurement Model

\begin{tabular}{|c|c|c|c|c|}
\hline Concept & Dimension & $\begin{array}{c}\text { Indicator of } \\
\text { dimension }\end{array}$ & Scale & Questionnaire \\
\hline \multirow{9}{*}{$\begin{array}{l}\text { Strategic } \\
\text { Motivation }\end{array}$} & \multirow{7}{*}{$\begin{array}{l}\text { Classification } \\
\text { of Incentives }\end{array}$} & \multirow{4}{*}{$\begin{array}{l}\text { Takeout } \\
\text { Incentive }\end{array}$} & \multirow{12}{*}{ 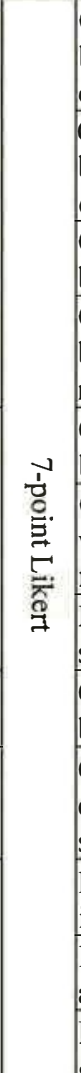 } & $\begin{array}{l}\text { Government-industry-academia collaboration is } \\
\text { beneficial in acquiring funds (subsidy) for the } \\
\text { development of water service technology. }\end{array}$ \\
\hline & & & & $\begin{array}{l}\text { Government-industry-academia collaboration is } \\
\text { beneficial in acquiring technology and knowledge } \\
\text { of water services. }\end{array}$ \\
\hline & & & & $\begin{array}{l}\text { Government-industry-academia collaboration is } \\
\text { beneficial for human resource education/cultivation. }\end{array}$ \\
\hline & & & & $\begin{array}{l}\text { Government-industry-academia collaboration is } \\
\text { beneficial for forming personal connection and } \\
\text { network. }\end{array}$ \\
\hline & & \multirow{3}{*}{$\begin{array}{l}\text { In-house } \\
\text { Incentive }\end{array}$} & & $\begin{array}{l}\text { Government-industry-academia collaboration is } \\
\text { beneficial for developing water services. }\end{array}$ \\
\hline & & & & $\begin{array}{l}\text { Government-industry-academia collaboration of } \\
\text { water services is necessary for water supply in the } \\
\text { future. }\end{array}$ \\
\hline & & & & $\begin{array}{l}\text { Participating in Government-industry-academia is } \\
\text { significant. }\end{array}$ \\
\hline & \multirow{2}{*}{$\begin{array}{l}\text { Classification } \\
\text { of Learning } \\
\text { motivation }\end{array}$} & Exploitation & & $\begin{array}{l}\text { Government-industry-academia collaboration will } \\
\text { bring in a concrete implementation. }\end{array}$ \\
\hline & & Exploration & & $\begin{array}{l}\text { Government-industry-academia collaboration is for } \\
\text { collecting information of water service technology's } \\
\text { study. }\end{array}$ \\
\hline \multirow{3}{*}{ Leadership } & & & & $\begin{array}{l}\text { In government-industry-academia collaboration, } \\
\text { industry mostly takes the leadership. }\end{array}$ \\
\hline & & & & $\begin{array}{l}\text { In government-industry-academia collaboration, } \\
\text { academia mostly takes the leadership. }\end{array}$ \\
\hline & & & & $\begin{array}{l}\text { In government-industry-academia collaboration, } \\
\text { government mostly takes the leadership. }\end{array}$ \\
\hline
\end{tabular}

\section{Analysis Results and Observations}

Based on the results of the questionnaire investigation of water supply corporations, PLS analysis is conducted to determine how strategic motivation factors influence the 
outcomes the number of times that government-industry-academia collaboration is carried out and water supply revenue trends.

As a result, as is shown in Table 3, the takeout incentive constituent elements "fundrelated advantages" $(\beta=0.68, p<0.05)$, "knowledge acquisition-related advantages" $(\beta=0.87, p<0.05)$, "human resources development-related advantages" $(\beta=0.91, p<0.05)$, and "network development-related advantages" $(\beta=0.83, p<0.05)$ each shows significance. Furthermore, the in-house incentive constituent elements "advantages for the growth of the waterworks industry" ( $\beta=0.95, p<0.05)$, "advantages for future water supply" $(\beta=0.96$, $p<0.05)$, and "value of participation in itself" $(\beta=0.69, p<0.05)$ also shows significance. In the area of strategy, the "commercialization-related advantages" exploitative strategy shows significance $(\beta=0.86, p<0.05)$, as does the explorative strategy of "research-related advantages" $(\beta=0.97, p<0.05)$.

With regard to leadership, "government's leadership" $(\beta=0.79, p<0.05)$ is shown to be significant, but "industry's leadership" $(\beta=-0.41, p>0.05)$ and "academia's leadership" $(\beta=0.51, p>0.05)$ were not significant. Furthermore regarding to outcomes, water supply revenue trends $(\beta=0.98, p<0.05)$ is shown to be significant, but the number of times that government-industry-academia collaboration is carried out $(\beta=0.23, p>0.05)$ does not contribute to the outcomes.

In the area of direct effects, Hypothesis 1 hypothesizes that takeout incentives will positively affect the outcomes. Contrary to expectations, takeout incentives have no significant relationship to the outcomes $(\beta=0.11, p>0.05)$. As a result, Hypothesis 1 is not supported.

Hypothesis 2 suggests that in-house incentives enhance the outcomes. Contrary to expectations, in-house incentives within the outcomes did not show significance either $(\beta=-0.35, p>0.05)$. As a result, Hypothesis 2 is not supported.

Hypothesis 3 hypothesizes positive impact of strategic motivations on the outcomes. Contrary to expectations, exploitative strategies and explorative strategies respectively does not show significance on the outcomes $(\beta=0.12, p>0.05)$. As a result, Hypothesis 3 is not supported.

With regard to indirect role, Hypothesis 4 hypothesizes that leadership will strengthen the positive relationship between takeout incentives and the outcomes. There was no significant relationship between takeout incentives and leadership in terms of its indirect role $(\beta=-0.03, p>0.05)$. As a result, Hypothesis 4 is not supported.

Hypothesis 5 suggests that leadership will strengthen the positive relationship between in-house incentives and the outcomes. The pass coefficient fiom in-house incentives to leadership is together with the pass coefficent fiom leadership to outcomes $(\beta=0.77)$ and $(\beta=0.43)$. These are found to be significant with a significance level of $(p<0.5)$, thereby supporting Hypothesis 5 .

Finally, Hypothesis 6 hypothesizes leadership will strengthen the positive relationship between strategic motivations and the outcomes. The relationship between strategic motivations and leadership does not show significance $(\beta=-0.27, p>0.05)$. As a result, Hypothesis 6 is not supported.

From the above information, it is found that in-house incentives do not have a direct effect on outcomes, but rather there is an indirect effect through "government leadership" mediation (intermediate variable). In other words, it has been made clear that in-house incentives contribute to government leadership, which is tied to outcomes (Table 4). 
Table 3 The factors affecting incentives/ motivation and leadership

\begin{tabular}{|c|c|c|c|c|c|c|c|}
\hline & $\begin{array}{l}\text { Original Sample } \\
\text { (0) }\end{array}$ & $\begin{array}{l}\text { Sample Mean } \\
\text { (MI) }\end{array}$ & $\begin{array}{l}\text { Standard } \\
\text { Desiation } \\
\text { (STDEV) }\end{array}$ & $\begin{array}{l}\text { Standard Error } \\
\text { (STERR) }\end{array}$ & $\begin{array}{c}\text { T Statistics } \\
\text { (jO/STERR) }\end{array}$ & P value & \\
\hline $\begin{array}{l}\text { Network Development- } \\
\text { Related Advantages <- } \\
\text { Takeout Incentives }\end{array}$ & 0.834405 & 0.832666 & 0.065485 & 0.065485 & 12.742001 & $1.79 \mathrm{E}-17$ & $* *$ \\
\hline $\begin{array}{c}\text { Human Resourees } \\
\text { Development-Related } \\
\text { Advantages <- Takeout } \\
\text { Incentires }\end{array}$ & 0.913792 & 0.901243 & 0.044855 & 0.044855 & 20.372192 & $3.7 \mathrm{E}-26$ & $* *$ \\
\hline $\begin{array}{c}\text { Value of Participation } \\
\text { in Itself <- In-house } \\
\text { Inceutives }\end{array}$ & 0.697296 & 0.70275 & 0.122444 & 0.122444 & 5.694809 & $6.14 \mathrm{E}-07$ & $* *$ \\
\hline $\begin{array}{l}\text { Academin's Leadership } \\
\text { <- Leadership }\end{array}$ & 0.513504 & 0.403467 & 0.39026 & 0.39026 & 1.315798 & 0.194126 & \\
\hline $\begin{array}{l}\text { Government's } \\
\text { Leadership <- } \\
\text { Leadership }\end{array}$ & 0.795367 & 0.730618 & 0.212731 & 0.212731 & 3.738833 & 0.000469 & $* *$ \\
\hline $\begin{array}{l}\text { Commercialization- } \\
\text { Related Adyantages < } \\
\text { Learning Motivation }\end{array}$ & 0.862627 & 0.855716 & 0.152966 & 0.152966 & 5.639355 & 7.49E-07 & $* *$ \\
\hline $\begin{array}{l}\text { Advantages far Foture } \\
\text { Water Supply }<\text { In- } \\
\text { honse Incentives }\end{array}$ & 0.963597 & 0.952782 & 0.038088 & 0.038088 & 25.298945 & $1.58 \mathrm{E}-30$ & $* *$ \\
\hline $\begin{array}{l}\text { Advantages for the } \\
\text { Gronth of the } \\
\text { Waterworks Industry } \\
\text { \&-In-house Incentives }\end{array}$ & 0.958384 & 0.950894 & 0.035922 & 0.035922 & 26.679474 & $1.27 \mathrm{E}-31$ & $* *$ \\
\hline $\begin{array}{l}\text { Industry's Leadership } \\
<\text { - Leadership }\end{array}$ & -0.417149 & -0.34075 & 0.482432 & 0.482432 & 0.86468 & 0.391263 & \\
\hline $\begin{array}{l}\text { Number of Times tbat } \\
\text { Goverument-Industry- } \\
\text { Academia } \\
\text { Collaboration is } \\
\text { Carried out < } \\
\text { Outcomes }\end{array}$ & 0.233992 & 0.176177 & 0.633903 & 0.633903 & 0.369129 & 0.71356 & \\
\hline $\begin{array}{l}\text { Knossledge Acquisition- } \\
\text { Related Advantages <- } \\
\text { Takeout Incentives }\end{array}$ & 0.879065 & 0.871551 & 0.055692 & 0.055692 & 15.784316 & $2.86 \mathrm{E}-21$ & $* *$ \\
\hline $\begin{array}{c}\text { Research-Related } \\
\text { Advantages <- } \\
\text { Learring Motivation }\end{array}$ & 0.977424 & 0.938684 & 0.090841 & 0.090841 & 10.759759 & IE-14 & $* *$ \\
\hline $\begin{array}{l}\text { Water Supply Revenue } \\
\text { Trends }<\text { - Outcomes }\end{array}$ & 0.982593 & 0.718386 & 0.31417 & 0.31417 & 3.127589 & 0.002911 & $* *$ \\
\hline $\begin{array}{l}\text { Fund-Related } \\
\text { Advantages <- Takeout } \\
\text { Incentives }\end{array}$ & 0.686498 & 0.673472 & 0.134411 & 0.134411 & 5.10746 & 4.92E-06 & $* *$ \\
\hline
\end{tabular}

Table 4 Effects of incentives/motivation and leadership on outcomes

\begin{tabular}{|c|c|c|c|c|c|c|}
\hline & $\begin{array}{l}\text { Original Sample } \\
\text { (0) }\end{array}$ & $\begin{array}{l}\text { Sanuple Aiean } \\
\text { (M) }\end{array}$ & $\begin{array}{l}\text { Standard } \\
\text { Deriation } \\
\text { (STDEV) }\end{array}$ & $\begin{array}{c}\text { Standard Error } \\
\text { (STERR) }\end{array}$ & $\begin{array}{c}\text { TStatistics } \\
\text { (|O/STERR|) }\end{array}$ & \\
\hline $\begin{array}{l}\text { In-bouse Incentives -> } \\
\text { Leadership }\end{array}$ & 0.773316 & 0.694468 & 0.427861 & 0.427861 & 1.807401 & 0.0766 \\
\hline $\begin{array}{c}\text { In-bouse Incentives -> } \\
\text { Outcomes }\end{array}$ & -0.354265 & -0.259109 & 0.417799 & 0.417799 & 0.847932 & 0.400438 \\
\hline $\begin{array}{l}\text { Takeout Incentives -> } \\
\text { Leadership }\end{array}$ & -0.030386 & -0.013246 & 0.346234 & 0.346234 & 0.087763 & 0.930409 \\
\hline $\begin{array}{c}\text { Takeout Incentives -> } \\
\text { Outcomes }\end{array}$ & 0.11402 & 0.054138 & 0.380351 & 0.380351 & 0.299777 & 0.765566 \\
\hline $\begin{array}{l}\text { Leadership } \rightarrow \\
\text { Outcomes }\end{array}$ & 0.434922 & 0.391951 & 0.252449 & 0.252449 & 1.722809 & 0.090982 \\
\hline $\begin{array}{l}\text { Learning Motivation - } \\
>\text { Leadership }\end{array}$ & .0 .272624 & -0.249787 & 0.305033 & 0.305033 & 0.893752 & 0.375653 \\
\hline $\begin{array}{l}\text { Learning Motivation - } \\
>\text { Outcomes }\end{array}$ & 0.126807 & 0.105554 & 0.266076 & 0.266076 & 0.47658 & 0.635697 \\
\hline
\end{tabular}

$* * \mathrm{p}<0.05$ 


\section{Conclusion}

This study analyzed how the strategic motivation of government affects its outcome in government-industry-academia collaboration.

As a result, it is shown that takeout incentives, in-house incentives, explorative strategies and exploitative strategies have no direct linkage to the outcome of water supply revenue trends. However, it is made clear that the in-house incentives represented by the "advantages for the growth of the waterworks industry" and the "advantages for future water supply" are linked to the outcome represented by "water supply revenue trends" through the mediation of government leadership. In other words the future water supply and water works development awareness led to the collaborative willingness of water corporations (government). As a result, it can be concluded that when water corporations take leadership in the government-industry-academia collaboration, influence is exerted on water supply revenue trends (Figure 3).

Considering the results of this study, it is understood that the strategic motivation are not directly related to government-industry-academia collaboration outcomes, but rather it is the leadership of government leadership that is important for the outcomes.

Within this study, strategic motivation factors traditionally indicated within industryacademia collaborations that are thought to be takeout incentives, such as the academia strategic motivation factors represented by "the necessity of each university to secure outside funding" and the industry strategic motivation factors represented by "access to new research" and "new product and method development," are not recognized as having an impact on the outcomes of government-industry-academia collaboration. It can be considered that the differences in the perception of takeout incentives held by academia and industry and the exclusive perception of in-house incentives held by government have been clarified. It was also suggested that in managing the government-industryacademia collaboration it is necessary to be cautious of the differences in these perceptions.

Setting priorities to certain problems and reconciling conflicts in order to reach agreements, can be advanced only when there is some form of authority. (Barnard, 1938; Simon, 1947) Authority is effective when the authority that comes with the job positions are exercised together with leadership. Nishimura (2004) associated the authority that is derived from job position mainly with a collaborative domain and leadership solely with an autonomous domain in the autonomous collaboration system. Compared to cases of hierarchical organizations, the authority that comes with job positions for example in cooperative associations and during conferences are relatively unstable. This kind of instability can be decreased when a person with excellent leadership abilities is given due respect in the autonomous domain. Under turbulent circumstances, a member who possesses such a leadership authority will be strongly expected to take an important post in a collaborative domain.

Ishida (2004) investigated knowledge exchange that takes place within governmentindustry-academia collaborations from the viewpoint of the effectiveness of knowledge in research and development. In that study it was elucidated that differences in the actualization patterns of knowledge effectiveness are also brought about through disparities of the subjects' role in the leadership when promoting the governmentindustry-academia collaboration. The research also makes reference to leadership that brings about conformity to the knowledge effectiveness of subjects with differing 
expectations and actualizes effective knowledge exchange within the governmentindustry-academia collaboration.

This study analyzed the factors that motivate government to participation in government-industry-academia collaboration from the view of public entities represented by the water services. The study showed that in the public water services, government's motivation of common benefits leads it to take leadership which has an impact on the outcome,

On the other hand, it can also be said that government should play the main role in the collaboration under the circumstance where public water services own and manage and administer water facilities the argument of this study.

We have not analyzed whether the result obtained from this study is applicable to other cases related to government-industry-academia collaboration where government is not a main player in term of enterprise administration but only in charge of policy planning and giving subsidies. Moreover the issue of which participant should take the leadership role and how the strategic motivation of participants should be managed have not been explicitly made clear even though they are significant issues.

What's more is the necessity to analyse how the factor of motivation that lead to government-industry-academia collaboration in Japan's water services will influence the progress of overseas water business which is actively being expanded by governmentindustry collaboration.

Figure 3 Testing Hypotheses

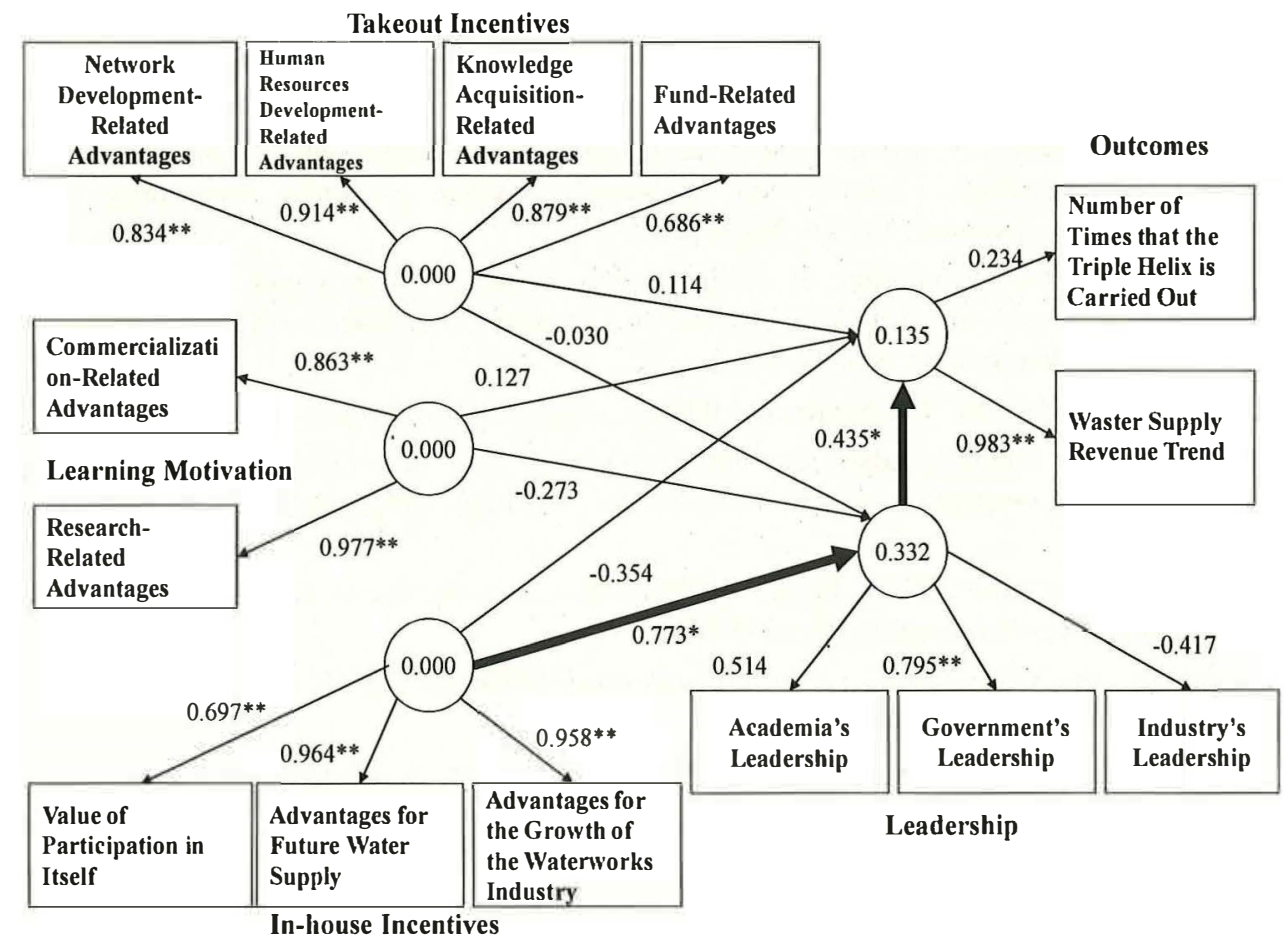




\section{References}

Baba, Y., Walsh, J.P., Yazaki, K., Suzuki, J., Gotou, A. (2007) Demonstration Research of Industry-Academia Cooperation. Tokyo University Shupankai.

Barclay, Donald and Brock Smith. (1997) 'The Effects of Organizational Differences and Trust on the Effectiveness of Selling Partner Relationships', Journal of Marketing 61(1), pp.3-21.

Barnard, C. I. (1938) The Function of the Executive, Harvard University Press.

Bleeke, Joel and David Ernst. (1991) 'The Way to Win in Cross-Border Alliance', Harvard Business review 69(6), pp.127-135.

Dussauge, P., B. Garrette, and W. Mitchell. (2000) 'Learning from Competing Partners: Outcomes and Durations of Scale and Link Alliances in Europe, North America and Asia', Strategic Management Journal, Vol.21, No.2, pp.99-126.

Harayama, Y., Waga, M., Kodama, S., Totu, K. (2003) Industry-Academia Cooperation: Towards Institutional Design to Increase Innovation. Toyo Keizai Shinpousha.

Hennart, J.F. (1998) 'A Transaction Costs Theory of Equity of Joint Ventures', Strategic Management Journal, Vol.9, No.4, pp.361-374, 1998.

Henry Etzkowitz. (2008) The Triple Helix: University-Industry-Government Innovation in action, New York. Taylor \& Francis Group, LLC.

Hulland, John. (1999) 'Use of Partial Least Squares (PLS) in Strategic Management Research: A Review of Four Recent Studies.' Strategic Management Journal, Vol.20, No.2, pp.195-204.

Ishida, S. (2004) 'Knowledge Interaction and Effectiveness in R\&D Triangular Partnership', Office Automation, Vol.19, NO.1, pp.65-72.

Japan Water Research Center (2011) Research on Pipeline Technology for Sustainable Drinking Water Services, Japan

Kamitani, K., Ishida, S. (2008) 'Inter-organizational Relationship between GovernmentIndustry-Academia Collaboration in Japan', Journal of Japan Association for Management Systems, Vol.24, No.2, pp.35-41.

Kanai, K. (2004) 'Promotion of Collaboration between Government, Industry and Academia, and the Function of "Ba" on Region', Ryukoku University business administration papers, Vol.44, No.3.

Khanna, Tarun. (1998) 'The Scope of Alliance', Organization Science 9 (3), pp.340-355.

Khanna, Tarun, Ranjay Gulati, and Nitin Nohria, (1998) 'The Dynamics of Learning Alliances: Competition, and Relative Scope', Strategic Management Journal 19 (3), pp.193-210.

Koza, Mitchell P. and Arie Y. Lewin. (1988) 'The Co-Evolution of Strategic Alliances', Organization Science 9 (3), pp.255-264.

Lohmoller, Jan-Bernd. (1989) Latent Variable Path Modeling With Partial Least Squares, New York: Springer-Verlag.

Lee, Y. S. (2000) 'The Sustainability of University-Industry Research Collaboration: An Empirical Assessment', Journal of Technology Transfer, Vol.25, pp.111-133.

March, J.G. (1991) 'Exploration and Exploitation in Organizational Learning', Organization Science, Vol.2, No.1, pp.71-87. 
Nishimura, T. (2004a) 'Autonomy and Collaboration on Region', Kushiro Public University Region Research, Vol.13, pp.147-161.

Nishimura, T. (2004b) 'Two Aspects in Inter-organization: Based on the Concept of Autonomous Collaborative System', Kushiro Public University Region Research, Vol.20, pp.75-91.

Nishimura, T. (2005) 'The Concept of Autonomous Collaborative System', Journal of Japan Association for Management Systems, Vol.22, No.1, pp.23-31.

Nishimura, T. (2010) 'Motivation and Compatibility about Alliance Partner', Kushiro Public University Region Research, Vol.19, pp.99-114.

Nonaka, I. (1991) 'The Introduction of Strategic Collaboration: Interorganizational Knowledge Creation and Communication', Business Review, Vol.38, No.4, pp.1-14.

Outaki, S., Kanai, K., Yamada, H., and Iwata, S. (1997) Management Strategy. Yuhikaku, Japan.

Parkhe, A. (1991) 'Interfirm Diversity, Organizational Learning, and Longevity in Global Strategic Alliances,' Journal of International Business Studies, Vol.22,No.4, pp.579601.

Sarker, M. B., R. Echambadi, S. T. Cavusgil, and P.S. Aulakh. (2001) 'The Influence of Complementarity, Compatibility, and Relationship Capital on Alliance Performance', Journal of the Academy of Marketing Science, Vol.29, No.4, pp. 358-373.

Simon, H. A. (1947) Administrative Behaviour, New York; Macmillan.

Teramoto, Y. and Nonaka, I. (1987) Interorganizational Network, Management, Tyuou Keizaisha, pp.205-230.

Watanabe, T., Inamura, Y., Ogura, M., Shindou, H., Tsujimoto, M., Tuyuki, E., and Tuyuki, M. Academic innovation, Hakutou-Shobo, 2008.

Water Industry Strategic Conference. (2008) Activity Plan 2008 in Water Industry: Reaction for Activity National Market and Expand International Market [online]. Federation of Japan Water Industries. INC. Available from: http:// www.suidanren.or.jp/committee/pdf/kasseika.pdf, 2008.[Accessed 14 April 2011]

Weick, K. E. (1976) 'Educational Organizational as Loosely Coupled Systems', Administrative Science Quarterly, Vol.21. No.1, pp.1-19.

Note

i The spiral platform of different but intertwined institutions presented by the triple helix framework helps to analyse the roles and relations of the various entities.

The triple helix was born through the need to analyse the relationship among government, universities, industries in different societies and also the various roles undertaken by government in the quest for creating innovation. 